Check for updates

Cite this: J. Mater. Chem. A, 2017, 5, 12506

Received 13th February 2017

Accepted 15th May 2017

DOI: $10.1039 / \mathrm{c} 7 \mathrm{ta0} 01352 \mathrm{c}$

rsc.li/materials-a

\section{Balancing the chemisorption and charge transport properties of the interlayer in lithium-sulfur batteries $\uparrow$}

\begin{abstract}
Liuqing Yang, Guochun Li, Xi Jiang, Tianran Zhang, Haibin Lin and Jim Yang Lee (D)*
This study introduces an improved design of the interlayer between the cathode and separator of rechargeable lithium-sulfur batteries to mitigate the polysulfide crossover problem of the latter. The design involves integrating carbon nanotubes with titanium dioxide by a facile room-temperature hydrolytic method to form a titanium dioxide coated carbon nanotube composite $\left.(\mathrm{CNTaTiO})_{2}\right)$ with customizable $\mathrm{TiO}_{2}$ content. The $\mathrm{CNTaTiO}$ composite was then coated on a separator to form an interlayer much thinner than other standalone interlayers. The $\mathrm{TiO}_{2}$ coating on the CNT surface provides the facility for lithium polysulfides (LiPS) interception by chemisorption, and the underlying CNT core renders the intercepted LiPS electrochemically viable in charging and discharging. A good balance between the chemisorption properties of $\mathrm{TiO}_{2}$ and the charge transport properties of the CNTs is required to deliver a good interlayer performance because of the complementarity of these functions. Consequently, a battery with an optimized $\mathrm{CNTCTiO}_{2}$ interlayer composition could deliver a high initial capacity of $1351 \mathrm{~mA} \mathrm{~h} \mathrm{~g}^{-1}$ and a discharge capacity of $803 \mathrm{~mA} \mathrm{~h} \mathrm{~g}^{-1}$ after 200 cycles at $0.1 \mathrm{C}$, for less than half of the thickness of a typical standalone interlayer $(12 \mu \mathrm{m})$.
\end{abstract}

\section{Introduction}

The interest in lithium-sulfur (Li-S) batteries is based on the very high theoretical specific capacity $\left(1675 \mathrm{~mA} \mathrm{~h} \mathrm{~g}^{-1}\right)$ and energy density $\left(2600 \mathrm{~W} \mathrm{~h} \mathrm{~kg}^{-1}\right)$ of sulfur as a cathode when it is paired with a Li metal anode..$^{1-6}$ The use of sulfur as the cathode also bestows other benefits such as low material cost and environmental benignity. ${ }^{7}$ Though promising, the development of Li-S batteries is impeded by several challenging technical issues. One of them is the insulating property of elemental sulfur and lithium sulfide (the discharge product) which necessitates the use of a large quantity of conductive additive (mostly carbon) in the cathode, and subsequently causes a reduction in the practical energy density. The other issue is the dissolution of the reaction intermediate products (lithium polysulfides (LiPS), $\mathrm{Li}_{2} \mathrm{~S}_{x}, 2<x \leq 8$ ) in the electrolyte, and their migration away from the cathode during battery operation. The LiPS migrate to the Li anode and passivate the latter by reduction and deposition. The gradual loss of active sulfur is a cause of significant capacity fading.

Many sulfur containment methods have been developed to improve the Li-S battery performance. Mesoporous and microporous carbon, ${ }^{8-10}$ hollow carbon spheres, ${ }^{11-16}$ and hollow

Department of Chemical and Biomolecular Engineering, National University of Singapore, 119260, Singapore.E-mail: cheleejy@nus.edu.sg

$\dagger$ Electronic supplementary information (ESI) available. See DOI: 10.1039/c7ta01352c carbon fibres ${ }^{17,18}$ are popular sulfur hosts because of their good electronic conductivity and their ability to physically adsorb polysulfides. However, the abundance of pores and a weak binding energy $(0.1-0.7 \mathrm{eV})$ between apolar carbon and polar LiPS cannot effectively suppress the leakage of LiPS, especially in a prolonged use. ${ }^{19-21}$ Recently, metal oxides and sulfides were introduced as sulfur hosts since their intrinsically polar surfaces should invoke a stronger interaction with the polysulfides. ${ }^{22-27}$ According to calculations, the binding energy between metal oxides/sulfides and LiPS is about 2.6-3.5 eV, much higher than the 0.1-0.7 eV binding energy between carbon and LiPS. ${ }^{28,29} \mathrm{Among}$ the metal oxides/sulfides, titanium dioxide $\left(\mathrm{TiO}_{2}\right)$ has drawn the most interest because of its availability, low cost, and ease of synthesis into various morphological forms. The low capacity fade rate $\left(0.033 \%\right.$ per cycle) of a sulfur- $\mathrm{TiO}_{2}$ cathode was attributed to its effective entrapment of polysulfides. ${ }^{22}$ However, the low conductivity of metal oxides and sulfides leads to a low rate performance and a low rate of sulfur utilization.

An alternative to the confinement of LiPS to a cathode host was demonstrated by the Manthiram group, who used a carbon paper as an interlayer between the cathode and separator and observed improvements in sulfur utilization and cycle life..$^{30,31}$ The carbon interlayer was believed to serve as an additional physical barrier to LiPS migration, and its conductivity allows the intercepted LiPS to be re-utilized electrochemically. Other interlayer materials have also been explored, including carbon nanofibers (CNFs) and carbon nanotubes (CNTs), ${ }^{32-37}$ nickel foam, ${ }^{38}$ mesoporous carbon,,$^{39,40}$ and conductive carbon 
powders. ${ }^{41-43}$ While some of them are self-standing layers, others form the interlayer by self-weaving (CNFs and long CNTs) or coating on the separator with a polymer binder. Since chemisorption could enhance LiPS retention, metal oxides/ sulfides such as tungsten disulfide, ${ }^{44}$ zinc oxide, ${ }^{45}$ tin oxide, ${ }^{46}$ cobalt disulfide ${ }^{47}$ manganese oxide, ${ }^{48}$ and $\mathrm{TiO}_{2}$ (ref. $49-52$ ) were later added to the interlayer. Recently Xu et al. deposited $\mathrm{a} \mathrm{TiO}_{2}$ layer on a carbon paper and investigated the adsorption properties of the interlayer formed as such in Li-S batteries. ${ }^{50}$ Later Liang et al. also reported the LiPS entrapment properties of a CNF paper decorated with $\mathrm{TiO}_{2}$ nanoparticles. ${ }^{51}$ Both of these studies demonstrated the use of chemisorption to improve the performance of $\mathrm{Li}-\mathrm{S}$ batteries. Since the low intrinsic conductivity of $\mathrm{TiO}_{2}$ can adversely affect the reutilization of LiPS, the balance between chemisorption and charge transport properties should be an important consideration in interlayer fabrication. In addition, since most carbon-based interlayers are fabricated as standalone components, their thickness often ranges from a few tens to hundreds of $\mu \mathrm{m}$. The considerable thickness can cause a notable decrease of the practical energy density. ${ }^{33}$ The preparation of the above-mentioned $\mathrm{TiO}_{2}$-decorated interlayers also involves high temperature annealing, which adds complexity and cost to the interlayer production. The development of a facile and low-cost method to fabricate thin interlayers with an adjustable metal oxide content is therefore of practical significance. Such an ability would also allow the effects of metal oxide/sulfide loading on the interlayer performance to be studied systematically.

Herein, we present a facile method which can deposit $\mathrm{TiO}_{2}$ on CNTs to different thicknesses (CNT@TiO ${ }_{2}$, Fig. 1a) at room

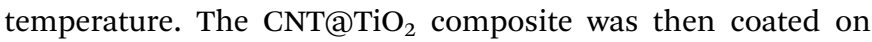
a battery separator and used as a thin interlayer for LiPS adsorption and reutilization. In the interlayer, the $\mathrm{TiO}_{2}$ coating on the CNTs provided the facility for strong LiPS chemisorption, while the underlying CNT core provided the electrical connectivity for the electrochemical conversion of the intercepted LiPS. The balance between chemisorption and charge transport performance was varied by adjusting the $\mathrm{TiO}_{2}$ layer thickness, thereby enabling the evaluation of the effectiveness of the CNT@ $\mathrm{TiO}_{2}$ interlayers and the effect of $\mathrm{TiO}_{2}$ loading on the $\mathrm{Li}-\mathrm{S}$ battery performance. Compared with a standalone interlayer, the interlayer fabricated this way could be as thin as $12 \mu \mathrm{m}$, and yet effective in improving the battery performance. This $\mathrm{CNT@TiO}_{2}$ interlayer could deliver 12.6\% more discharge capacity than a CNT interlayer, and the same rate performance as what was previously only possible with thick interlayers.

\section{Experimental}

\section{Chemicals}

Lithium foil (99.9 wt\% metal basis, $0.75 \mathrm{~mm}$ thick, Li), bis(trifluoromethane)sulfonimide lithium salt (99.95 wt\% trace metals basis, LiTFSI), 1,2-dimethoxyethane (99.5 wt\% anhydrous, DME), 1,3-dioxolane (99.8 wt\% anhydrous, DOL), lithium nitrate (99.99 wt\% trace metals basis, $\mathrm{LiNO}_{3}$ ), 1-methyl-2pyrrolidinone (99.5 wt\%, NMP), ammonium hydroxide solution (28.0-30.0 wt\% $\mathrm{NH}_{3}$ basis), titanium diisopropoxide bis(acetylacetonate) (75 wt $\%$ in isopropanol, $\mathrm{Ti}(\mathrm{acac})_{2} \mathrm{OiPr}_{2}$ ) and sulfur ( $\geq 99.5 \mathrm{wt} \%$ ) were from Sigma-Aldrich; isopropyl alcohol (HPLC, IPA) was from TEDIA; Celgard 2325 membranes were from Celgard LLC; gas diffusion layers (NOS1005) were from GasHub Technology Pte Ltd; Super-P carbon was from Imerys Graphite \& Carbon; and carbon nanotubes (CNTs) were from Nanjing XFNANO Materials Tech. Co; all of them were used as received. Deionized water (DIW) from an Elga Micromeg Deionizer was used as the universal solvent.

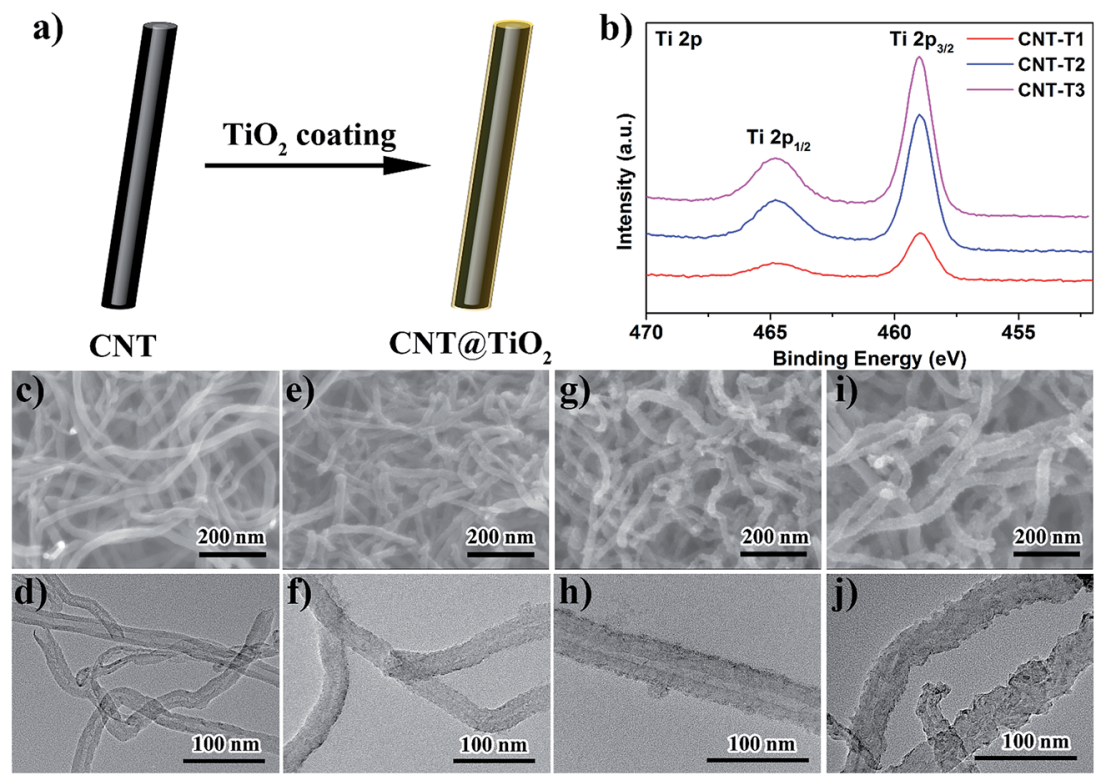

Fig. 1 (a) Schematic of the $\mathrm{TiO}_{2}$ coating on CNTs. (b) XPS Ti 2p spectra of different CNT $\left(\mathrm{aTiO} \mathrm{O}_{2}\right.$ composites. FESEM and TEM images of pristine CNTs (c and d), CNT-T1 (e and f), CNT-T2 ( $g$ and h) and CNT-T3 ( $i$ and j). 


\section{Synthesis of CNT@TiO ${ }_{2}$ composites}

CNT@TiO ${ }_{2}$ composites with adjustable $\mathrm{TiO}_{2}$ loadings were prepared by a modified sol-gel method. ${ }^{22}$ In a typical preparation, $128 \mathrm{mg}$ CNTs were ultrasonically dispersed in $80 \mathrm{~mL}$ IPA, $20 \mathrm{~mL}$ DIW, and $2 \mathrm{~mL}$ ammonium hydroxide solution for $2 \mathrm{~h} .50$ $\mathrm{mL} 0.02 \mathrm{M} \mathrm{Ti}(\mathrm{acac})_{2} \mathrm{OiPr}_{2}$ solution in IPA was then added in 4 batches $(12.5 \mathrm{~mL} \times 4)$ at $30 \mathrm{~min}$ apart and vigorously stirred.

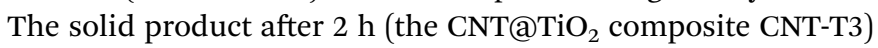
was centrifugally separated, washed with IPA several times, and vacuum dried. Two other composites namely CNT-T2 and CNT$\mathrm{T} 1$ were similarly prepared using different quantities of the $0.02 \mathrm{M} \mathrm{Ti}(\text { acac })_{2} \mathrm{OiPr}_{2}$ IPA solution $(25 \mathrm{~mL}$ in twice $(12.5 \mathrm{~mL} \times 2)$ and $12.5 \mathrm{~mL}$ in once, respectively).

\section{Preparation of thin $\mathrm{CNT}_{\mathrm{TTiO}}$ interlayers}

The CNT@TiO ${ }_{2}$ composite prepared above was mixed with PVDF in a $90: 10$ weight ratio and added to a $1: 1(\mathrm{v} / \mathrm{v})$ mixture of ethanol and NMP to form a slurry by vigorous stirring. The slurry was spread with a doctor-blade on a Celgard separator and vacuum dried at $80{ }^{\circ} \mathrm{C}$ for $12 \mathrm{~h}$ to form a thin interlayer on the separator. The $\mathrm{CNT} \mathrm{TiO}_{2}$ interlayer coated separator prepared as such was hole punched into $19 \mathrm{~mm}$ diameter disks for assembly into Li-S batteries. Celgard membrane separators coated with only the CNT interlayer were also prepared for

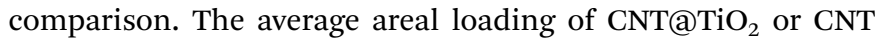
was about $0.7 \mathrm{mg} \mathrm{cm}^{-2}$.

\section{Preparation of the sulfur cathode}

A commercial sulfur powder was first ball-milled with Super-P carbon in a $2: 1$ weight ratio. The sulfur content in the mixture as measured by thermal gravimetric analysis (TGA) was $66.4 \mathrm{wt} \%$ (Fig. S1 $\dagger$ ). The sulfur/carbon mixture was then mixed with PVDF in a $9: 1$ weight ratio, and dispersed in NMP to form a cathode slurry after vigorous overnight stirring. The final sulfur : Super-P carbon : PVDF ratio in the cathode was $60: 30: 10$ by weight. The homogenous slurry was coated on a gas diffusion layer (used as the current collector) with a doctor blade, to a controlled sulfur loading of $\sim 1.7 \mathrm{mg} \mathrm{cm}^{-2}$. Some cathodes were also prepared with a higher sulfur loading of $\sim 3 \mathrm{mg} \mathrm{cm}^{-2}$. The sulfur electrode was then cut into $12 \mathrm{~mm}$ diameter disks after vacuum drying at $55^{\circ} \mathrm{C}$ for $12 \mathrm{~h}$.

\section{Cell assembly and electrochemical tests}

CR2025-type stainless steel coin cells were assembled in an argon-filled glove box where the moisture and oxygen levels were below $1 \mathrm{ppm}$ each. The cells consisted of a Li foil anode, the sulfur cathode, and a $1 \mathrm{M}$ LiTFSI electrolyte in a $1: 1(\mathrm{v} / \mathrm{v})$ mixture of DOL and DME with $0.2 \mathrm{M} \mathrm{LiNO}_{3}$ additive. Celgard membranes coated with different types of interlayers were used as the separator with the interlayer facing the sulfur cathode. Batteries with only the Celgard separator were also assembled for comparison.

The batteries were discharged and charged galvanostatically at room temperature on a NEWARE BTS- $5 \mathrm{~V}$ battery tester in the 1.7-2.6 V voltage window at different $\mathrm{C}$ rates $(0.1-1 \mathrm{C}$, where $1 \mathrm{C}$ $=1675 \mathrm{~mA} \mathrm{~h} \mathrm{~g}^{-1}$ based on the theoretical capacity of sulfur).
The measured capacities were all normalized by the weight of sulfur. Cyclic voltammograms and electrochemical impedance spectra (EIS) were recorded using a $\mu$ AUTOLAB TYPE III potentiostat/galvanostat electrochemical workstation with a FRA2 module. The cyclic voltammograms (CVs) were recorded at a scan rate of $0.1 \mathrm{mV} \mathrm{s}^{-1}$ in the $1.7-2.6 \mathrm{~V}$ voltage window. EIS measurements were carried out under open circuit conditions from $10 \mathrm{mHz}$ to $100 \mathrm{kHz}$.

\section{Characterization}

The sulfur content in the sulfur/Super-P carbon mixture and the

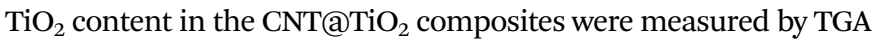
in air on a Shimadzu DTG-60AH (Shimadzu Company, Japan) at the heating rate of $10{ }^{\circ} \mathrm{C} \mathrm{min}^{-1}$. X-ray diffraction patterns of the composite powders were recorded using a Bruker D8 advance X-ray diffractometer with $\mathrm{Cu} \mathrm{K} \alpha$ radiation (1.5405 ̊). Field emission scanning electron microscope (FESEM) images were taken on a JEOL 7200 microscope. Energy-dispersive X-ray spectroscopic (EDX) elemental analysis was performed during the SEM sessions by in situ EDX on a JEOL JSM-5600LV microscope operating at 15 $\mathrm{kV}$. Transmission electron microscopy (TEM) was performed on a JEOL JEM 2010 microscope operating at $200 \mathrm{kV}$. X-ray photoelectron spectroscopy (XPS) measurements were carried out on a Kratos Axis Ultra DLD spectrometer. Binding energies were corrected by referencing the $\mathrm{C} 1 \mathrm{~s}$ peak of adventitious carbon to $284.5 \mathrm{eV}$.

\section{Results and discussion}

\section{$\mathrm{CNT@TiO}_{2}$ composites and interlayers}

$\mathrm{CNT@TiO}_{2}$ composites with different $\mathrm{TiO}_{2}$ loadings were prepared by the direct hydrolysis of $\mathrm{Ti}(\text { acac })_{2} \mathrm{OiPr}_{2}$ in the presence of CNTs at room temperature, using the amount of $\mathrm{Ti}(\mathrm{acac})_{2} \mathrm{OiPr}_{2}$ to vary the coating thickness. The successful coating of CNTs with $\mathrm{TiO}_{2}$ in all three $\mathrm{CNT@TiO}{ }_{2}$ composites was confirmed by the presence of Ti 2 p peaks in the XPS survey spectrum (Fig. S2 $\dagger$ ) and in the Ti 2p region (Fig. 1b). The $\mathrm{TiO}_{2}$ loadings in the composites as determined by TGA (Fig. S3a $\dagger$ ) were $13.2 \mathrm{wt} \%$ for CNT-T1, $21.4 \mathrm{wt} \%$ for CNT-T2, and $33.0 \mathrm{wt} \%$ for CNT-T3. Morphology examination by FESEM and TEM showed that the smooth surface of the original $20 \mathrm{~nm}$ CNTs (Fig. 1c and d) was coarsened after the deposition of $\mathrm{TiO}_{2}$. Nonetheless the deposition was uniform on the CNT surface to give rise to the appearance of a thin coating (Fig. 1e-j). The uniform deposition of $\mathrm{TiO}_{2}$ on CNTs was driven by two factors the abundance of oxygenated functional groups on the CNT surface (Fig. S2 $\dagger$ ) which enabled the CNTs to disperse well in the IPA/water solution and promoted the heterogeneous nucleation of $\mathrm{TiO}_{2}$ and its growth into an adherent layer. The rate of $\mathrm{Ti}$ (acac) ${ }_{2} \mathrm{OiPr}_{2}$ hydrolysis was also made more uniform by dispensing the $\mathrm{Ti}(\mathrm{acac})_{2} \mathrm{OiPr}_{2}$ in batches. The coating "thickness" increased from an average value of $\sim 4 \mathrm{~nm}$ in CNT-T1 (Fig. 1f) to $6 \mathrm{~nm}$ in CNT-T2 (Fig. 1h) and $10 \mathrm{~nm}$ in CNT-T3 (Fig. 1j). The increase in coating thickness also increased the apparent surface roughness. XRD analysis of the coated CNTs (Fig. S3b $\dagger$ ) detected only the diffraction from CNTs. The 

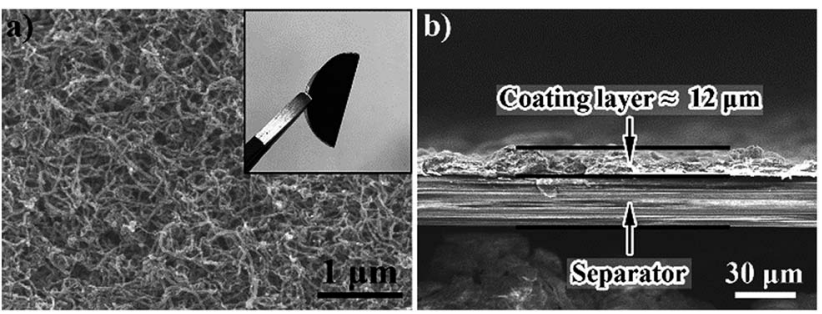

Fig. 2 (a) A low-magnification FESEM image of the top-view of a CNTT2 interlayer on the Celgard separator. The inset shows the bendability of the CNT-T2 coated separator. (b) The cross-sectional FESEM image of the CNT-T2 interlayer on the separator.

absence of $\mathrm{TiO}_{2}$ diffraction suggests that the as-synthesized $\mathrm{TiO}_{2}$ was amorphous, which is typical for $\mathrm{TiO}_{2}$ prepared from the sol-gel method. ${ }^{22}$

An interlayer on the separator was formed by casting the CNT@TiO ${ }_{2}$ composite onto the separator surface using the doctor blade technique. All $\mathrm{CNT}_{\mathrm{NTiO}}$ interlayers on the separator surface had the same appearance as the low magnification FESEM images of the CNT-T2 interlayer in Fig. 2. Fig. 2a shows that the $\mathrm{TiO}_{2}$-coated CNTs intertwined with one another into a dense and crack-free uniform heap on the separator surface. The flexion of the separator was not compromised due to the good adhesion, thinness and elasticity of the CNT-based coating with a PVDF binder. Unlike the standalone interlayers in previous studies which require a thickness of tens to hundreds of $\mu \mathrm{m}$ to support their construction and cell assembly, the doctor blade coating technique allows the interlayer to be thinned to the $\mu \mathrm{m}$ level to minimize any adverse effect on $\mathrm{Li}^{+}$transport and total energy density. Fig. $2 \mathrm{~b}$ shows that the CNT-T2 interlayer was only $12 \mu \mathrm{m}$ thick, about half of the thickness of the Celgard separator.

\section{Electrochemical performance}

The electrochemical performance of $\mathrm{Li}-\mathrm{S}$ batteries with different types of interlayers on the Celgard separators was compared to evaluate the effectiveness of the ${\mathrm{CNT} @ \mathrm{TiO}_{2}}_{2}$ interlayer and the effect of $\mathrm{TiO}_{2}$ loading. The sulfur content and electrolyte in the test batteries were kept approximately the same in the comparison, and so was the interlayer thickness (all were about $12 \mu \mathrm{m}$, as shown in Fig. 2b). Fig. 3a shows the Nyquist plots of newly assembled batteries with the different interlayers. The large charge transfer resistance (the largest semicircle in the high-frequency region) of the battery with only the Celgard separator was due to the low conductivity of sulfur. The addition of a CNT-only conductive interlayer decreased the charge transfer resistance substantially, as it was functionally similar to the use of excess carbon in the sulfur cathode. While the CNT conductivity was lowered by the presence of a $\mathrm{TiO}_{2}$ layer on the CNT surface, batteries with $\mathrm{CNT}_{0} \mathrm{TiO}_{2}$ interlayers still showed a lower charge transfer resistance than the battery with only the Celgard separator, indicating that the CNTs were electrically accessible. Previous research has shown that even with a thick poorly conductive coating $(25 \mathrm{~nm})$ on the CNT surface, the composite could still support electron transport with an overall electronic conductivity of $\sim 0.001 \mathrm{~S} \mathrm{~m}^{-1}$. $^{53}$ The charge transfer resistance of batteries with different interlayers decreased in the following order: CNT $<$ CNT-T1 $<$ CNT-T2 $<$ CNT-T3 < Celgard, as would be expected from the increasing thickness of the $\mathrm{TiO}_{2}$ coating on the CNTs.

The cyclic voltammograms of the CNT-T3 interlayer and of $\mathrm{Li}-\mathrm{S}$ batteries with different interlayers at $0.1 \mathrm{mV} \mathrm{s}^{-1}$ for the first three cycles are compared in Fig. S4. $\dagger$ Even with the use of an interlayer with the highest $\mathrm{TiO}_{2}$ content (CNT-T3), no redox reaction was detected within the test voltage window, and hence

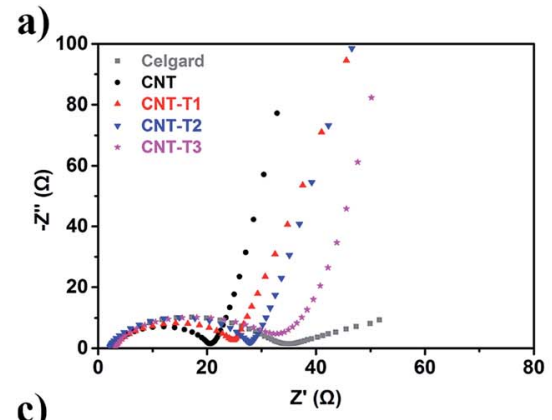

c)

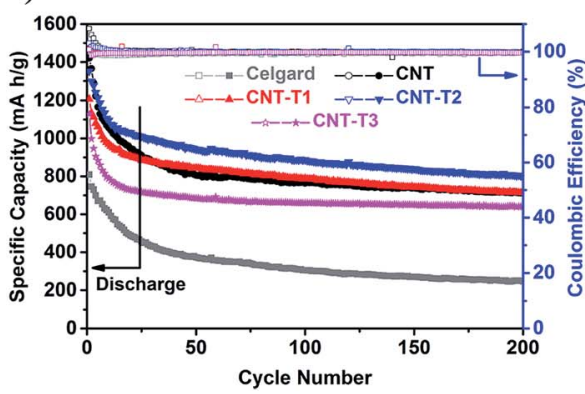

b)
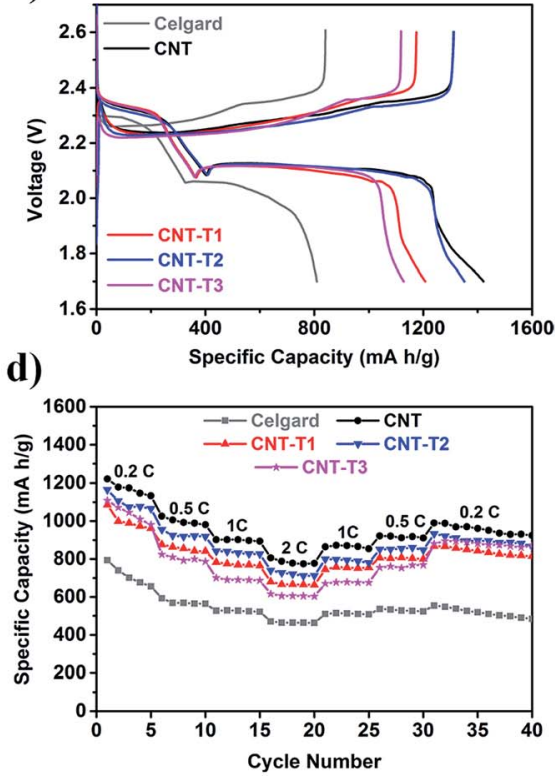

Fig. 3 (a) Nyquist plots of newly assembled Li-S batteries using different interlayers. (b) $1^{\text {st }}$ cycle galvanostatic discharge-charge curves of Li-S batteries with different interlayers at 0.1C. (c) Cycling performance of Li-S batteries with different interlayers at $0.1 \mathrm{C}$ and (d) comparison of their rate performance. 
$\mathrm{TiO}_{2}$ would not contribute to the capacity of the test batteries. This was also confirmed by the detection of only the redox reactions of sulfur in the $\mathrm{Li}-\mathrm{S}$ test batteries (Fig. S4b-f $\dagger$ ). Fig. $3 \mathrm{~b}$ shows the $1^{\text {st }}$ cycle galvanostatic discharge-charge voltage curves of $\mathrm{Li}-\mathrm{S}$ batteries with different interlayers at $0.1 \mathrm{C}(1 \mathrm{C}=$ $1675 \mathrm{~mA} \mathrm{~h} \mathrm{~g}^{-1}$ ). Relative to the battery without any interlayer, all

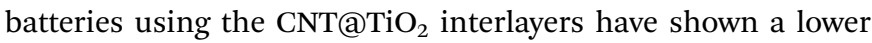
charge plateau, a higher discharge plateau and a more extended second-discharge plateau at $\sim 2.1 \mathrm{~V}$ (corresponding to the further reduction of long-chain LiPS into short-chain LiPS and lithium disulfide/sulfide), which are indications of more facile redox reactions and higher sulfur utilization. The cycling performance of these batteries was compared at 0.1C. Fig. 3c shows that, with only the pristine Celgard separator, the $\mathrm{Li}-\mathrm{S}$ battery could only deliver an initial discharge capacity of 809 $\mathrm{mA} \mathrm{h} \mathrm{g}^{-1}$, or $48.3 \%$ of sulfur utilization. Due to the absence of any means of polysulfide retention (in the sulfur cathode or the separator), the uninhibited dissolution of LiPS and the formation of solid sulfur species not connected to the conducting network during cycling resulted in the loss of active sulfur to decrease the capacity to $246 \mathrm{~mA} \mathrm{~h} \mathrm{~g}^{-1}$ after 200 cycles $(30.4 \%$ capacity retention). Sulfur utilization was improved by the presence of a conductive interlayer between the sulfur cathode and the separator, where the overall decrease in charge transfer resistance could help the conversion of wayward sulfur species. Thus, the battery with the most conductive interlayer (CNT only) showed the highest initial discharge capacity of $1421 \mathrm{~mA} \mathrm{~h} \mathrm{~g}^{-1}$, $713 \mathrm{~mA} \mathrm{~h} \mathrm{~g}^{-1}$ of which was retained after 200 cycles, which is a significant improvement over the battery using the pristine

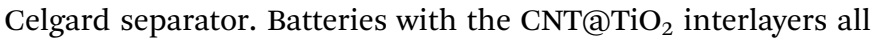
performed better than the battery with only a Celgard separator. It is worth mentioning that discharge capacity faded rather sharply in the first 15 cycles, similar to the observation in a previous study. ${ }^{50}$ This could be attributed to the initial loss of sulfur caused by the formation of LiPS in the cathode and on the interlayer surface. Though the battery with the Celgard separator only exhibited fast capacity decay in the first few cycles, the lower rate of capacity fading actually reflects a lower rate of sulfur utilization. Once the interlayer had accumulated a sufficient quantity of LiPS, further dissolution of LiPS was inhibited due to the common-ion effect. ${ }^{54}$ The stabilization of capacity after 15 cycles was therefore an indication of LiPS in dynamic

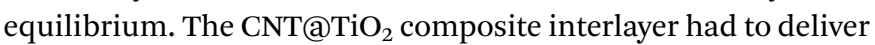
both strong LiPS chemisorption and low charge transfer resistance - the former for LiPS retention to deliver a stable cycling performance, and the latter for sulfur re-utilization to increase the Li-S battery storage capacity. Thus a balance is essential because the low conductivity of $\mathrm{TiO}_{2}$ could increase the charge transfer resistance. The $\mathrm{TiO}_{2}$ loading on CNTs had to be regulated to deliver a satisfactory outcome. The good performance of the battery using the Celgard separator with an intermediate $\mathrm{TiO}_{2}$ loading in the interlayer $\left(21.4 \mathrm{wt} \% \mathrm{TiO}_{2}, \mathrm{CNT}-\mathrm{T} 2\right)$ could be reasoned as such. The chemisorbed LiPS on $\mathrm{TiO}_{2}$ was rendered electrochemically viable by the conductivity of the underlying CNTs, and could be further reduced to lithium disulfide/sulfide (during discharge) or oxidized to sulfur (during charge) while maintaining the equilibrium adsorption of LiPS on $\mathrm{TiO}_{2}$. This battery delivered an initial capacity of $1351 \mathrm{~mA} \mathrm{~h} \mathrm{~g} \mathrm{~g}^{-1}$ and a discharge capacity of $803 \mathrm{~mA} \mathrm{~h} \mathrm{~g}^{-1}$ after 200 cycles at $0.1 \mathrm{C}$. Its steady state capacity represents a $12.6 \%$ improvement over the battery with the CNT interlayer. The battery with the CNT-T1 interlayer was similar to the CNT-interlayered battery, suggesting that the increase in charge transfer resistance was duly compensated by increased utilization of the LiPS by chemisorption. On the other hand, the battery with the CNT-T3 interlayer (highest $\mathrm{TiO}_{2}$ loading) delivered a capacity of only $638 \mathrm{~mA} \mathrm{~h} \mathrm{~g}^{-1}$ after 200 cycles, an indication of overcompensation of LiPS chemisorption at the expense of charge transfer resistance. The high coulombic efficiency $(>99.5 \%)$ in all batteries could be accredited to the addition of $0.2 \mathrm{M} \mathrm{LiNO}_{3}$ to the electrolyte.

The rate capability of these batteries was then measured at different current densities (Fig. 3d), and the following decreasing order was found: Celgard $<$ CNT-T3 $<$ CNT-T1 $<$ CNT$\mathrm{T} 2<\mathrm{CNT}$. The battery with the CNT-T2 interlayer delivered the second highest rate performance (740 $\mathrm{mA} \mathrm{h} \mathrm{g}{ }^{-1}$ at $\left.2 \mathrm{C}\right)$. This

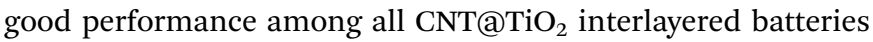
is yet another display of the "balance" between LiPS chemisorption and charge transport properties. The CNT-T2 layer also worked well when the sulfur loading was increased to $3 \mathrm{mg}$ $\mathrm{cm}^{-2}-969 \mathrm{~mA} \mathrm{~h} \mathrm{~g}^{-1}$ at $0.2 \mathrm{C}$ after the first cycle activation, and $783 \mathrm{~mA} \mathrm{~h} \mathrm{~g}{ }^{-1}$ after 100 cycles, as shown in Fig. 4a. Capacity retention was $80.9 \%$ at $0.2 \mathrm{C}$ for 100 cycles, corresponding to a coulombic efficiency higher than $99.5 \%$ for each cycle. The performance of the CNT-T2 interlayered battery with a sulfur loading of $1.7 \mathrm{mg} \mathrm{cm}^{-2}$ in prolonged cycling (1000 cycles) at 0.5 and $1 \mathrm{C}$ was also examined (Fig. $4 \mathrm{~b}$ ). The capacity at $0.5 \mathrm{C}$ also displayed some initial rapid decline due to the same LiPS equilibration process discussed earlier in the cycling of the battery at $0.1 \mathrm{C}$. While it took 15 cycles to reach LiPS equilibrium at $0.1 \mathrm{C}, 50$ cycles were needed for $0.5 \mathrm{C}$, suggesting that the equilibrium process was mainly time dependent. From the $50^{\text {th }}$ to the $1000^{\text {th }}$ cycle, capacity declined from $783 \mathrm{~mA} \mathrm{~h} \mathrm{~g}^{-1}$ to 541 $\mathrm{mA} \mathrm{h} \mathrm{g}^{-1}$. The average capacity fade rate throughout the test was about $0.057 \%$ per cycle. Even at the high $1 \mathrm{C}$ rate, a discharge capacity of $525 \mathrm{~mA} \mathrm{~h} \mathrm{~g}^{-1}$ was still available after 1000 cycles, corresponding to a capacity fade rate of $\sim 0.056 \%$ per cycle. The coulombic efficiencies in these tests were all higher than 99\%. Table $\mathrm{S} 1 \dagger$ compares the electrochemical performance of $\mathrm{Li}-\mathrm{S}$ batteries with different carbon-based
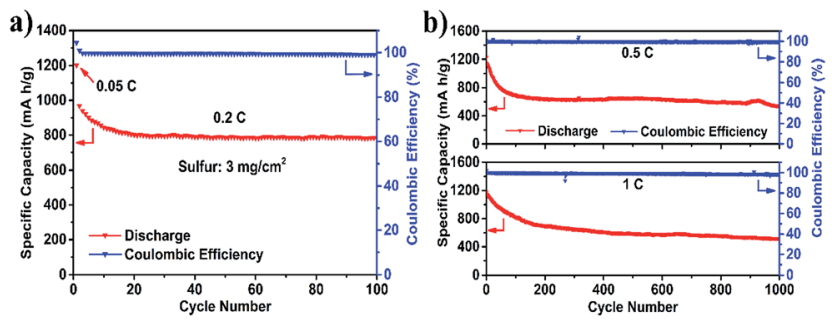

Fig. 4 (a) Cycling performance of a Li-S battery with the CNT-2 interlayer at a sulfur loading of $3 \mathrm{mg} \mathrm{cm}^{-2}$. (b) The long-term performance of $\mathrm{Li}-\mathrm{S}$ batteries with the CNT-T2 interlayer and a sulfur loading of $1.7 \mathrm{mg} \mathrm{cm}^{-2}$ at 0.5 and $1 \mathrm{C}$. 


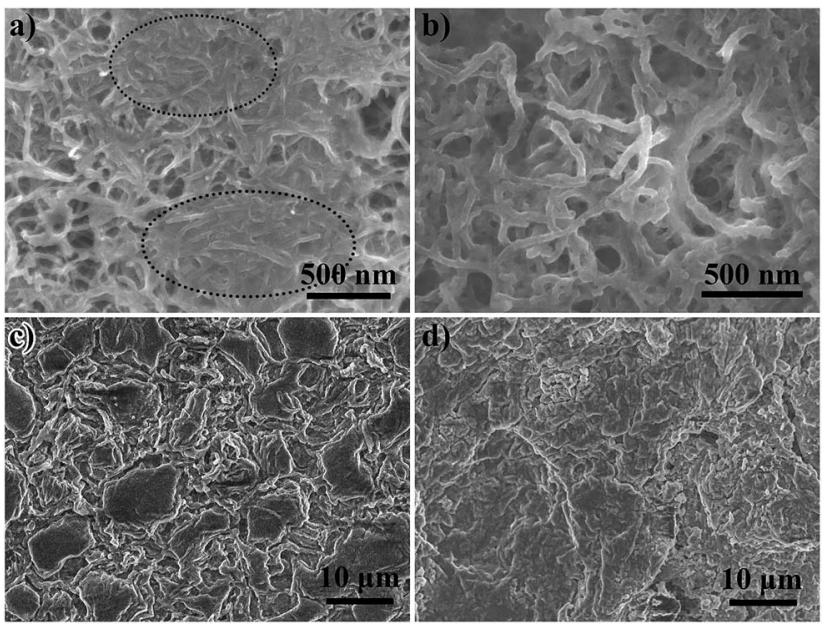

Fig. 5 The FESEM images of cycled (a) CNT interlayer, (b) CNT-T2 interlayer, and ( $c$ and d) the correspondingly cycled Li anode.

interlayers researched in recent years. The simpler design presented in this study was able to provide a comparable performance.

A CNT interlayer, a CNT-T2 interlayer, and their corresponding Li anodes at the end of the $1000^{\text {th }}$ charge cycle at $0.5 \mathrm{C}$ were examined by FESEM. The microscopy samples were washed copiously with DOL to remove the electrolyte and soluble polysulfides. The sulfur species in the interlayer should consist only of the fully oxidized form of physically trapped and chemisorbed sulfur species, i.e. elemental sulfur. The low affinity between carbon and polysulfides led to the formation of sulfur in aggregated forms in the interlayer, as shown in the oval areas in Fig. 5a. The apparent diameter of the CNTs also grew to $\sim 55 \mathrm{~nm}$ due to the sulfur deposition (Fig. 5b). On the contrary, the chemisorption of LiPS on $\mathrm{TiO}_{2}$ enabled the active sulfur species to distribute well in the CNT-T2 layer, and oxidize to sulfur on the surface. Consequently, no sulfur aggregation areas were found. EDX spectroscopy also confirmed the uniform distribution of sulfur in the cycled CNT-T2 interlayer (Fig. S5†). Since the CNT interlayer only entrapped migratory LiPS by physical forces, a sufficiently large amount of LiPS could still cross over to the Li anode and affect the SEI formation process there. ${ }^{55}$ This can be seen from the presence of coarse Li particles and a higher degree of roughness of the Li anode surface cycled with the CNT interlayer (Fig. 5c). These were products of parasitic reactions between dissolved LiPS and Li metal during cycling. On the contrary, the Li anode cycled with the CNT-T2 interlayer had a smoother surface (Fig. $5 \mathrm{~d}$ ). This is an indication of the successful alleviation of polysulfide crossover by the interlayer, thereby minimizing their interference with the $\mathrm{Li}$ metal surface corrosion and regeneration processes.

\section{Conclusions}

In summary, $\mathrm{CNT} @ \mathrm{TiO}_{2}$ composites with different $\mathrm{TiO}_{2}$ coating thicknesses on the CNT surface were prepared by a facile hydrolytic reaction, and cast onto Celgard battery separators as integrated thin interlayers to improve the performance of $\mathrm{Li}-\mathrm{S}$ batteries. The $\mathrm{TiO}_{2}$ coating on the CNTs provided the facility for LiPS chemisorption, while the underlying conductive CNT core rendered the intercepted LiPS electrochemically viable. A balance between the chemisorption properties of $\mathrm{TiO}_{2}$ and the charge transport properties of the CNTs is needed, and this was achieved experimentally by tuning the $\mathrm{TiO}_{2}$ layer thickness. The battery using the interlayer with an optimized $\mathrm{TiO}_{2}$ loading could deliver a discharge capacity of $803 \mathrm{~mA} \mathrm{~h} \mathrm{~g}^{-1}$ after 200 cycles at $0.1 \mathrm{C}$. The discharge capacity was $525 \mathrm{~mA} \mathrm{~h} \mathrm{~g}^{-1}$ after 1000 cycles at 1C for a small capacity fade rate of $0.056 \%$ per cycle. The study shows the possibility of building a thin but effective interlayer for fast charge transport and good polysulfide retention through interlayer composition optimization.

\section{Acknowledgements}

The authors gratefully acknowledge the financial support provided by the National Research Foundation, Prime Minister's Office, Singapore under its Competitive Research Program (CRP Award No. NRF-CRP8-2011-04).

\section{References}

1 Y. X. Yin, S. Xin, Y. G. Guo and L. J. Wan, Angew. Chem., Int. Ed., 2013, 52, 13186-13200.

2 A. Manthiram, Y. Fu, S. H. Chung, C. Zu and Y. S. Su, Chem. Rev., 2014, 114, 11751-11787.

3 Z. W. Seh, Y. Sun, Q. Zhang and Y. Cui, Chem. Soc. Rev., 2016, 45, 5605-5634.

4 Z. Li, H. B. Wu and X. W. Lou, Energy Environ. Sci., 2016, 9, 3061-3070.

5 D.-W. Xu, S. Xin, Y. You, Y. Li, H.-P. Cong and S.-H. Yu, ChemNanoMat, 2016, 2, 712-718.

6 G. C. Li, H. K. Jing, Z. Su, C. Lai, L. Chen, C. C. Yuan, H. H. Li and L. Liu, J. Mater. Chem. A, 2015, 3, 11014-11020.

7 A. Earnshaw and N. Greenwood, in Chemistry of the Elements, Butterworth-Heinemann, Oxford, 2nd edn, 1997, ch. 15, pp. 645-746.

8 X. Li, Y. Cao, W. Qi, L. V. Saraf, J. Xiao, Z. Nie, J. Mietek, J.-G. Zhang, B. Schwenzer and J. Liu, J. Mater. Chem., 2011, 21, 16603-16610.

9 X. Ji, K. T. Lee and L. F. Nazar, Nat. Mater., 2009, 8, 500-506. 10 J. Schuster, G. He, B. Mandlmeier, T. Yim, K. T. Lee, T. Bein and L. F. Nazar, Angew. Chem., Int. Ed., 2012, 51, 3591-3595.

11 N. Jayaprakash, J. Shen, S. S. Moganty, A. Corona and L. A. Archer, Angew. Chem., Int. Ed., 2011, 50, 5904-5908.

12 K. Zhang, Q. Zhao, Z. Tao and J. Chen, Nano Res., 2013, 6, 3846.

13 C. Zhang, H. B. Wu, C. Yuan, Z. Guo and X. W. Lou, Angew. Chem., Int. Ed., 2012, 51, 9592-9595.

14 S. Chen, X. Huang, B. Sun, J. Zhang, H. Liu and G. Wang, J. Mater. Chem. A, 2014, 2, 16199-16207.

15 G. He, S. Evers, X. Liang, M. Cuisinier, A. Garsuch and L. F. Nazar, ACS Nano, 2013, 7, 10920-10930.

16 F. Xu, Z. Tang, S. Huang, L. Chen, Y. Liang, W. Mai, H. Zhong, R. Fu and D. Wu, Nat. Commun., 2015, 6, 7221. 
17 G. Zheng, Y. Yang, J. J. Cha, S. S. Hong and Y. Cui, Nano Lett., 2011, 11, 4462-4467.

18 S. Moon, Y. H. Jung, W. K. Jung, D. S. Jung, J. W. Choi and D. K. Kim, Adv. Mater., 2013, 25, 6547-6553.

19 J. Liu, W. Li, L. Duan, X. Li, L. Ji, Z. Geng, K. Huang, L. Lu, L. Zhou, Z. Liu, W. Chen, L. Liu, S. Feng and Y. Zhang, Nano Lett., 2015, 15, 5137-5142.

20 S. Zhang, S. Tsuzuki, K. Ueno, K. Dokko and M. Watanabe, Angew. Chem., Int. Ed., 2015, 54, 1302-1306.

21 G. Zheng, Q. Zhang, J. J. Cha, Y. Yang, W. Li, Z. W. Seh and Y. Cui, Nano Lett., 2013, 13, 1265-1270.

22 Z. Wei Seh, W. Li, J. J. Cha, G. Zheng, Y. Yang, M. T. McDowell, P.-C. Hsu and Y. Cui, Nat. Commun., 2013, 4, 1331.

23 Z.-Z. Yang, H.-Y. Wang, L. Lu, C. Wang, X.-B. Zhong, J.-G. Wang and Q.-C. Jiang, Sci. Rep., 2016, 6, 22990.

24 Z. Liang, G. Zheng, W. Li, Z. W. Seh, H. Yao, K. Yan, D. Kong and Y. Cui, ACS Nano, 2014, 8, 5249-5256.

25 Z. Li, J. Zhang, B. Guan, D. Wang, L.-M. Liu and X. W. Lou, Nat. Commun., 2016, 7, 13065.

26 X. Liang, C. Y. Kwok, F. Lodi-Marzano, Q. Pang, M. Cuisinier, H. Huang, C. J. Hart, D. Houtarde, K. Kaup, H. Sommer, T. Brezesinski, J. Janek and L. F. Nazar, Adv. Energy Mater., 2016, 6, 1501636.

27 X. Wang, G. Li, J. Li, Y. Zhang, A. Wook, A. Yu and Z. Chen, Energy Environ. Sci., 2016, 9, 2533-2538.

28 Q. Pang, X. Liang, C. Y. Kwok and L. F. Nazar, Nat. Energy, 2016, 1, 16132.

29 Q. Zhang, Y. Wang, Z. W. Seh, Z. Fu, R. Zhang and Y. Cui, Nano Lett., 2015, 15, 3780-3786.

30 Y.-S. Su and A. Manthiram, Nat. Commun., 2012, 3, 1166.

31 C. Zu, Y. S. Su, Y. Fu and A. Manthiram, Phys. Chem. Chem. Phys., 2013, 15, 2291-2297.

32 Z. Wang, J. Zhang, Y. Yang, X. Yue, X. Hao, W. Sun, D. Rooney and K. Sun, J. Power Sources, 2016, 329, 305-313.

33 R. Singhal, S.-H. Chung, A. Manthiram and V. Kalra, J. Mater. Chem. A, 2015, 3, 4530-4538.

34 Q. Li, M. Liu, X. Qin, J. Wu, W. Han, G. Liang, D. Zhou, Y.-B. He, B. Li and F. Kang, J. Mater. Chem. A, 2016, 4, 12973-12980.

35 S. H. Chung and A. Manthiram, J. Phys. Chem. Lett., 2014, 5, 1978-1983.

36 S.-H. Chung, P. Han, R. Singhal, V. Kalra and A. Manthiram, Adv. Energy Mater., 2015, 5, 1500738.
37 J.-Y. Hwang, H. M. Kim, S.-K. Lee, J.-H. Lee, A. Abouimrane, M. A. Khaleel, I. Belharouak, A. Manthiram and Y.-K. Sun, Adv. Energy Mater., 2016, 6, 1501480.

38 K. Zhang, F. Qin, J. Fang, Q. Li, M. Jia, Y. Lai, Z. Zhang and J. Li, J. Solid State Electrochem., 2014, 18, 1025-1029.

39 J. Balach, T. Jaumann, M. Klose, S. Oswald, J. Eckert and L. Giebeler, J. Phys. Chem. C, 2015, 119, 4580-4587.

40 J. Balach, T. Jaumann, M. Klose, S. Oswald, J. Eckert and L. Giebeler, Adv. Funct. Mater., 2015, 25, 5285-5291.

41 H. Yao, K. Yan, W. Li, G. Zheng, D. Kong, Z. W. Seh, V. K. Narasimhan, Z. Liang and Y. Cui, Energy Environ. Sci., 2014, 7, 3381-3390.

42 N. Liu, B. Huang, W. Wang, H. Shao, C. Li, H. Zhang, A. Wang, K. Yuan and Y. Huang, ACS Appl. Mater. Interfaces, 2016, 8, 16101-16107.

43 D. Zhao, X. Qian, L. Jin, X. Yang, S. Wang, X. Shen, S. Yao, D. Rao, Y. Zhou and X. Xi, RSC Adv., 2016, 6, 13680-13685. 44 J. Park, B.-C. Yu, J. S. Park, J. W. Choi, C. Kim, Y.-E. Sung and J. B. Goodenough, Adv. Energy Mater., 2017, 1602567, DOI: 10.1002/aenm.201602567.

45 T. Zhao, Y. Ye, X. Peng, G. Divitini, H.-K. Kim, C.-Y. Lao, P. R. Coxon, K. Xi, Y. Liu, C. Ducati, R. Chen and R. V. Kumar, Adv. Funct. Mater., 2016, 26, 8418-8426.

46 J. Liu, L. Yuan, K. Yuan, Z. Li, Z. Hao, J. Xiang and Y. Huang, Nanoscale, 2016, 8, 13638-13645.

47 Z. Ma, Z. Li, K. Hu, D. Liu, J. Huo and S. Wang, J. Power Sources, 2016, 325, 71-78.

48 X. Qian, L. Jin, D. Zhao, X. Yang, S. Wang, X. Shen, D. Rao, S. Yao, Y. Zhou and X. Xi, Electrochim. Acta, 2016, 192, 346-356.

49 Z. Xiao, Z. Yang, L. Wang, H. Nie, M. E. Zhong, Q. Lai, X. Xu, L. Zhang and S. Huang, Adv. Mater., 2015, 27, 2891-2898.

50 G. Xu, J. Yuan, X. Tao, B. Ding, H. Dou, X. Yan, Y. Xiao and X. Zhang, Nano Res., 2015, 8, 3066-3074.

51 G. Liang, J. Wu, X. Qin, M. Liu, Q. Li, Y.-B. He, J.-K. Kim, B. Li and F. Kang, ACS Appl. Mater. Interfaces, 2016, 8, 2310523113.

52 M. S. Kim, L. Ma, S. Choudhury and L. A. Archer, Adv. Mater. Interfaces, 2016, 3, 1600450.

53 F.-F. Cao, Y.-G. Guo, S.-F. Zheng, X.-L. Wu, L.-Y. Jiang, R.-R. Bi, L.-J. Wan and J. Maier, Chem. Mater., 2010, 22, 1908-1914.

54 R. Xu, I. Belharouak, J. C. M. Li, X. Zhang, I. Bloom and J. Bareño, Adv. Energy Mater., 2013, 3, 833-838.

55 C. Yan, X.-B. Cheng, C.-Z. Zhao, J.-Q. Huang, S.-T. Yang and Q. Zhang, J. Power Sources, 2016, 327, 212-220. 